\title{
COMUNICAÇÃO COMO TECNOLOGIA SOCIAL PARA O DESENVOLVIMENTO: PROPOSTA METODOLÓGICA PARA AVALIAÇÃO DA ESTRUTURA DE COMUNICAÇÃO DE UM TERRITÓRIO
}

\author{
Communication as social technology: a methodological proposal to evaluate the \\ communication structure of a territory
}

\section{Comunicación como tecnología social: propuesta metodológica para evaluar la estructura de comunicación de un território}

Monica Franchi Carniello Doutora em Comunicação e Semiótica, professora do Mestrado em Planejamento e Desenvolvimento Regional da Universidade de Taubaté. monicafcarniello@gmail.com

Moacir José dos Santos Doutor em História, professor do Mestrado em Planejamento e Desenvolvimento Regional da Universidade de Taubaté. professormoacirsantos@gmail.com

\section{Resumo}

A comunicação é um dos fatores que incide sobre os processos de desenvolvimento de um território e um aspecto de interesse estratégico para um país. A questão central é identificar quando e como um ambiente comunicacional é favorável para o desenvolvimento. Parte-se da premissa teórica de que a comunicação deve operar como uma Tecnologia Social para cumprir seu papel de vetor do desenvolvimento. O objetivo geral deste artigo é propor um método para avaliação da estrutura e fluxos de comunicação de determinados territórios para verificar se esta cumpre um papel favorável ao desenvolvimento. A pesquisa caracteriza-se como exploratória, de abordagem qualitativa e delineamento bibliográfico. A proposta metodológica aproxima referentes à estrutura de mídia das premissas da Tecnologia Social.

Palavras-chave: Desenvolvimento territorial. Comunicação. Tecnologia social.

\begin{abstract}
Communication is one of the factors that focuses on the development processes of a territory and an aspect of strategic interest for a country. The central question is to identify when and how a communicational environment is conducive to development. It is based on the theoretical premise that communication must operate as a Social Technology to fulfill its role as a vector of development. The main objective of this article is to propose a method to evaluate the structure and communication flows of certain territories to verify if it fulfills a development-friendly role. The research is characterized as exploratory, with a qualitative approach and a bibliographic delineation. The methodological proposal approximates the media structure with the premises of Social Technology.
\end{abstract}


Key words: Territorial development. Communication. Social technology.

\section{Resumen}

La comunicación es uno de los factores que incide sobre los procesos de desarrollo de un territorio y un aspecto de interés estratégico para un país. La cuestión central es identificar cuándo y cómo un ambiente comunicacional es favorable para el desarrollo. Se parte de la premisa teórica de que la comunicación debe operar como una Tecnología Social para cumplir su papel de vector del desarrollo. El objetivo general de este artículo es proponer un método para evaluar la estructura y flujos de comunicación de determinados territorios para verificar si ésta cumple un papel favorable al desarrollo. La investigación se caracteriza como exploratoria, de abordaje cualitativo y delineamiento bibliográfico. La propuesta metodológica aproxima referentes a la estructura de contenido media de las premisas de la Tecnología Social.

Palabras clave: Palabra clave. Palabra clave. Palabra clave.

\section{INTRODUÇÃO}

A acelerada evolução tecnológica, vivenciada de forma mais enfática a partir do século XX, culminou em um protagonismo da tecnologia na sociedade contemporânea, que passou a ser um valor, tanto em termos econômicos quanto socioculturais. $\mathrm{O}$ fato de a inovação tecnológica ser capaz, entre outras aplicações, de gerar produtos, resultou na apropriação de inovações tecnológicas pelos detentores dos meios de produção daquelas tecnologias que se mostraram mercadologicamente viáveis. Gerou-se, a partir deste raciocínio, a valoração de alguns tipos de tecnologias e a omissão de outras que, por distintas razões, não despertaram interesse das empresas sob o prisma mercadológico.

A ciência, sob certo aspecto, tornou-se refém da tecnologia, fenômeno identificado e nominado por Postman (1994, p.31) como tecnopólio, que retoma as ideias marxistas ao perceber que "as tecnologias criam as maneiras com as quais as pessoas percebem a realidade, e que essas maneiras são a chave para compreender diversas formas de vida social e mental". A supervalorização de determinadas tecnologias impacta também na compreensão de ciência.

Observa-se uma valorização de áreas do conhecimento que potencialmente podem gerar tecnologias, que por sua vez, podem, por vezes, gerar produtos mercadologicamente viáveis em detrimento a outras que podem gerar outros tipos de conhecimento ou tecnologias que possuem menor apelo de mercado, seja por questões de custo, por dificuldades de produção e distribuição ou, em última instância, pela potencialidade de confrontar o sistema de produção e de mercado instituídos. No campo da ciência, para validar a perspectiva funcionalista, cria-se o mito de que ciência e tecnologia, indistintamente, seriam capazes de 
sanar os problemas do subdesenvolvimento. Dagnino (2000) e Herrera (1981) se opõem de forma contundente a esta ideia, visto que esta premissa oportunamente mascara as causas dos baixos níveis de desenvolvimento de determinados territórios, especialmente as contradições econômicas. Os rótulos de neutralidade e imparcialidade são comumente atribuídos à ciência para justificá-la de forma acrítica, transferindo esta ilusória imagem para a tecnologia. Em tempo, adota-se o pressuposto de que a ciência está sujeita à historicidade, o que elimina qualquer possibilidade de neutralidade. O mesmo se aplica à tecnologia.

Posto este cenário, torna-se possível inferir que as tecnologias que não atendem aos mercados ficam em segundo plano, não interessam àqueles que detêm os meios de produção, especialmente as potencializadoras da organização social dedicada ao combate das assimetrias sociais. Portanto, as tecnologias de infraestrutura ou de promoção de igualdade social, por exemplo, e que atendem aos pobres, que por lógica são mercados menos interessantes para a maior parte das empresas, são menos valorizadas ou mesmo invisíveis para a maior parte da sociedade. Enquadram-se entre as tecnologias de menor valoração as chamadas tecnologias sociais, foco teórico deste estudo, compreendidas como fator promotor de organização social e apropriação coletiva de saberes relacionados à promoção da qualidade de vida e alternativas à concepção de que os problemas sociais são resolvidos exclusivamente no mercado.

O fenômeno de valorização de determinadas tecnologias se capilarizou nas mais diversas áreas de atuação humana, e de forma bem evidente nos processos de comunicação, inicialmente pela popularização dos meios eletrônicos (rádio e televisão) e, a partir do final do século XX, pelas mídias digitais, cuja centralidade estrutural se baseia na rede mundial de computadores. Tomando como premissa a tese de Postman (1994) de que há uma valoração e apropriação das tecnologias que podem ser comercialmente exploradas, infere-se que as Tecnologias de Comunicação e Informação (TIC) foram amplamente difundidas pelo fato de as TIC terem sido estruturadas como um modelo de negócio altamente rentável. A mercantilização da tecnologia é claramente visível no cenário da comunicação contemporânea ao verificar o protagonismo de algumas empresas privadas na organização dos fluxos de comunicação global, como é o caso do Facebook, que anunciou via assessoria de imprensa possuir 2 bilhões de usuários no mundo (G1, 2017).

Em suma, a comunicação mediada tornou-se altamente complexa com a difusão das TIC, como aponta Pross (apud MENEZES, 2004) ao categorizar as mídias em primárias, secundárias e terciárias, conforme o uso de aparatos por parte de emissor e/ou receptor para efetivar os processos de comunicação. Para o autor, os fluxos de comunicação que demandam 
aparatos tanto do emissor quanto do receptor enquadram-se mídia terciária, amplamente presente no ambiente midiático contemporâneo em função das mídias eletrônicas e digitais. As mídias adquiriram o status de elemento essencial da dinâmica social contemporânea e permeiam os mais diversos tipos de relação e interação. Alçados à condição de indústria, os produtos comunicacionais possuem valor de mercado, visto que se organizam em empresas que entendem a comunicação como um negócio.

Exposto o contexto comunicacional contemporâneo e sua relação com a tecnologia, retoma-se a ideia fundamental de que a comunicação é a base e o instrumento de qualquer relacionamento e organização social, para introduzir a seguinte reflexão: será que as estruturas de comunicação atuais são favoráveis ao desenvolvimento de determinado território? Em linhas gerais, em uma perspectiva macro, permite-se formular a hipótese de que não o são em sua maioria, visto que as tecnologias de comunicação foram apropriadas pelo mercado, o que resulta em concentração de capital, e não o bem-estar social, objetivo último do desenvolvimento. Se, por um lado, a perspectiva macro nos leva a este raciocínio, por outro, há de se considerar que há especificidades e, portanto, heterogeneidade nas estruturas de comunicação dos territórios, bem como apropriações distintas das estruturas macro pelas populações locais.

Ao partir da premissa de que a questão local é relevante e fundamental no processo de desenvolvimento de territórios, conforme ressalta Boudin (2001), e que há territórios com melhores níveis de desenvolvimento em comparação a outros, formula-se a questão central deste artigo: como avaliar se os processos e estrutura de comunicação de um território cumprem um papel favorável ao desenvolvimento?

A partir da questão norteadora, foi definido o objetivo geral deste artigo: propor um método para avaliação da estrutura e fluxos de comunicação de determinados territórios para verificar se esta cumpre um papel favorável ao desenvolvimento.

Parte-se do pressuposto que há uma estrutura favorável de comunicação para o desenvolvimento quando esta se aproxima das premissas da tecnologia social, visto que são tecnologias favorecem o alcance do objetivo maior do desenvolvimento: o bem-estar social. Para estabelecer esta relação, o referencial teórico foi conduzido de maneira a suportar conceitualmente os parâmetros de análise sugeridos neste artigo de caráter exploratório, ao abordar as bases conceituais de tecnologia social e da relação entre comunicação e desenvolvimento. 


\section{COMUNICAÇÃO PARA O DESENVOLVIMENTO}

A comunicação não existe fora da interseção da linguagem com a técnica (Breton, 1997) e, no ambiente contemporâneo, com a tecnologia, que de manifesta nos meios de comunicação impressos, eletrônicos e digitais.

Para debater a relação entre comunicação e desenvolvimento, faz-se necessário, primeiramente, admitir o caráter paradoxal das mídias, que são parte da estrutura da sociedade contemporânea. Lipovetsky (2004) explicita a ambiguidade das mídias ao rejeitar a perspectiva meramente apocalíptica, que culpa a mídia por todas as mazelas sociais, e revelar seus inegáveis efeitos na sociedade: a individualização e a ampliação das possibilidades de comparação de pontos de vista. Por um lado, a mídia desempenhou um papel de individualização e disseminação hedônica que inicialmente rompeu com instituições e algumas restrições socialmente definidas e limitou a sociabilidade por mecanicamente concentrar o foco de atenção nos conteúdos veiculados, minimizando a relevância de outros lugares de sociabilidade (cafés, igrejas...). Por outro, “a mídia 'mecanicamente' abre os horizontes de cada um [...] os indivíduos estão, agora, em condições de estabelecer comparações entre eles mesmos e os outros, entre o aqui e o distante, o hoje e o ontem" (LIPOVETSKY, 2004, pp. 72-73).

Uma segunda premissa fundamental para que seja possível relacionar comunicação e desenvolvimento é de que a cultura é um fator e vetor de desenvolvimento. Essa perspectiva demanda a superação de visões consolidadas nos campos disciplinares sobre o que vem a ser desenvolvimento e rompe com uma visão meramente economicista de desenvolvimento. Dallabrida (2011, p. 282) reforça esta relação ao afirmar que na definição de desenvolvimento, ao diferenciar-se de crescimento econômico e contemplar a noção de mudanças estruturais nas dimensões econômicas, sociais, culturais e tecnológicas, não só há uma relação entre economia, cultura e desenvolvimento. A dimensão econômica e a cultura são elementos constitutivos dos processos de desenvolvimento, junto com a dimensão social, política, espacial, ecológica e tecnológica.

Como pilar conceitual desta seção, faz-se necessário também conceituar desenvolvimento. Furtado (1964) apresenta o conceito de desenvolvimento econômico, em superação à sinonímia entre crescimento econômico e desenvolvimento. O desenvolvimento econômico está associado à distribuição de renda e à qualidade de vida, ponto de convergência com outros autores que tratam do tema, tais domo Deaton (2013), que destaca as desigualdades sociais que se mantém a despeito do crescimento econômico. Sen (2000) faz 
uma associação entre desenvolvimento e eliminação das restrições sociais dos indivíduos, o que lhes permitiria a livre escolha de que tipo de vida gostariam de ter. Os objetivos do desenvolvimento incluem o aprimoramento das condições materiais para todos: mais equidade no acesso aos recursos e riquezas naturais; atendimento aos direitos humanos; liberdade e securidade; aprimoramento das escolhas e empoderamento para influenciar as próprias condições de vida; e sustentabilidade. São objetivos que dificilmente serão alcançados em sua plenitude e de forma contínua, mas que envolvem processos contínuos de diálogo, negociação e tomada de decisão, todos estes fundamentados nos processos de comunicação (PANOS LONDON, 2007).

As mídias compreendidas como elemento constitutivo da sociedade contemporânea, caracterizam-se como um dos aspectos culturais e tecnológicos intervenientes nos processos de desenvolvimento. Dado o caráter paradoxal das mídias previamente esclarecido, estabelecer uma relação entre comunicação e desenvolvimento implica, necessariamente, em buscar compreender as complexidades e as formas como as estruturas de comunicação se estabelecem em determinado território, para verificar se estas se apresentam como favoráveis para o alcance de aspectos fundamentais do desenvolvimento. Conforme Bringe (2006), o papel das mídias como únicas definidoras da comunicação já havia sido questionado por Jesus Martin Barbero no final dos anos 1980, o que permite refletir sobre como a comunicação se posiciona em relação ao desenvolvimento.

Em uma abordagem mais simplista, conforme destaca Lubetkin (2008), há uma compreensão particular sobre a relação comunicação e desenvolvimento ao identificar como objetivo desta relação é precisamente por os cidadãos em contato com os dramas e os problemas das populações desfavoráveis do planeta para contribuir com a criação de uma opinião pública favorável para dotar de instrumentos e recursos a cooperação internacional. Esta visão parece incompelta, pois não abarca as relações de poder que existem entre aqueles que são proprietários dos meios de produção de conteúdo. Causar comoção pode ser uma forma de espetacularizar algo (DEBORD, 2000) e de silenciar outros aspectos e não considera as estruturas e relações de poder que estão imbricadas no sistema de mídia de determinado território.

Já Guareschi (2013, p.23), ao argumentar em favor da democratização dos meios de comunicação, estabelece uma interface clara entre comunicação e desenvolvimento. O autor parte da identificação do que é chamado de quarta geração de direitos, que "se colocam na consciência cada vez maior dos seres humanos no seu desejo e necessidade de participar 
ativamente não apenas de espaços políticos e burocráticos, mas também na criação de espaços que vêm responder a necessidades mais profundas de liberdade e autonomia”. Tal processo só pode ser alcançado por meio da comunicação, esta também entendida como um direito básico. Guareschi (2013) evidencia a contradição do cenário midiático brasileiro, ao observar que, apesar de os marcos legais brasileiros apontarem para orientações avançadas e progressistas, tal qual se apresenta a Constituição de 1988, a prática comunicativa se dá "de maneira completamente diversa e constituindo-se numa das mais conservadoras da América Latina" (GUARESCHI, 2013, p.39). Tal contexto se apresenta como uma barreira para o estabelecimento de uma relação profícua entre comunicação e desenvolvimento. Lima (2006) destaca que a mídia no Brasil , além de ser centralizada em decorrência da ausência de limites à propriedade cruzada, está se internacionalizando a partir de parcerias com megaempresas globais do setor de comunicação.

Wolton (2005) aborda o cenário global de comunicação, ao discutir as mudanças ocorridas no cenário comunicacional contemporâneo. questiona como reconciliar a realidade técnica e econômica da comunicação com sua dimensão cultural, social e política. Apesar de não fazer uso do termo desenvolvimento, a questão diz respeito aos usos e estruturas de comunicação para além das relações de mercado, tão evidentes e presentes na atualidade. $\mathrm{O}$ autor também reflete sobre as especificidades locais que se apresentam nos processos de comunicação, ao afirmar que "quanto mais as mensagens se mundializam, mais as diferenças culturais da comunicação se afirmam" (WOLTON, 2005, p.17) [tradução dos autores].

Bringe (2006) destaca alguns aspectos centrais da comunicação que a posicionam como elementos dos processos de desenvolvimento: a compreensão da comunicação não apenas como uma ferramenta e sim como uma dimensão sociocultural capaz de gerar transformações; a comunicação como interação entre indivíduos e grupos e não como ação meramente informativa; a existência de uma vontade de transformação.

A instituição Panos London (2007) destaca que a comunicação, elemento essencial das relações entre indivíduos e grupos, tem sido ignorada ou marginalizada nas análises, debates e intervenções de desenvolvimento. Entende que processos efetivos de informação e comunicação são pré-requisitos para o desenvolvimento de fato, pois são elementos diretamente relacionados à governança e empoderamento. Ressalta o desafio que se apresenta ao usar a comunicação como um agente de mudança para estabelecer um desenvolvimento mais sustentável. Para tal, identifica os processos de desenvolvimento nos quais a informação e comunicação são elementos chave: nos processos políticos equitativos; nos processos de 
governança nacionais e internacionais; no apoio ao engajamento dos cidadãos e na dinâmica da sociedade; na geração de crescimento econômico, meios de subsistência sustentáveis e transparentes e mercados eficientes e equitativos; no estabelecimento e proteção de um ambiente de mídia livre, plural, diversificado e com alta qualidade.

Comunicação e desenvolvimento são indissociáveis, pois qualquer processo de desenvolvimento é um ato coletivo, e não individual, e a comunicação é o meio pelo qual se difundem e introduzem as ideias nos grupos sociais. Porém, as condições inerentes à estrutura de comunicação contemporânea implicam na subordinação dos fluxos de comunicação e dos meios de produção de conteúdo à economia política do capital. Esse cenário corresponde ao domínio e à competição intercapitalista entre as grandes corporações de mídia no cenário internacional e à atuação dos grupos de comunicação relevantes em cada espaço nacional ou regional. A lógica econômica preponderante dissocia a comunicação dos processos de desenvolvimento ao definir como objetivo central a acumulação dos recursos necessários à perenidade de cada empresa na competição intercapitalista.

A comunicação enquanto fator de desenvolvimento demanda o suporte de políticas públicas adequadas a facilitar o acesso da população a formas de produção, disseminação e consumo de conteúdos necessários para a maior coesão social e a expressão das realidades regionais em suas múltiplas dimensões. Entretanto, a elaboração e a efetivação de políticas públicas aptas a estimular o potencial da comunicação para o desenvolvimento depende da interação entre os atores sociais e a complexidade inerente ao Estado, permeado por disputas políticas relativas ao seu controle.

A complexidade da inserção social da comunicação indica que sua contribuição para processos de desenvolvimento decorre da associação de fatores como: a estrutura de mídia presente em um determinado território; as características das políticas públicas para o setor; e a apropriação social da técnica, convertida em tecnologia social. Nesse sentido, a interação entre comunicação e desenvolvimento tem como fator fundamental a dimensão política, responsável por potencializar a apropriação do potencial comunicacional enquanto tecnologia social e favorecer o desenvolvimento territorial mediante a diversidade de acesso aos recursos comunicacionais.

\subsection{Comunicação como tecnologia social}

Primeiramente, faz-se necessário distinguir ciência de tecnologia, tarefa que conceitualmente é claramente delimitada, mas que ocorre de forma imbrincada em sua 
prática. Em função da supervalorização das tecnologias que podem ser apropriadas pelo mercado, as áreas do conhecimento que, por sua natureza e objetos de estudo podem gerar tais tecnologias ganham mais visibilidade, conforme Postman (1994).

A ciência básica tem por objetivo gerar conhecimento sobre quaisquer assuntos. A ciência aplicada diz respeito à resolução de problemas com os conhecimentos científicos, o que resulta na solução de um problema prático sem entrar no mérito das implicações socioeconômicas envolvidas. A partir do momento em que tais implicações são consideradas a solução torna-se uma tecnologia, como utilização, superando a simples aplicação (VARGAS, 2003). As tecnologias sociais levam em consideração as desigualdades sociais, que apesar de serem o reflexo mais evidente das lacunas do desenvolvimento de um território, são as que, mercadologicamente, geram menos interesse.

Fundamental ressaltar que a concepção que se adota sobre ciência é que esta não é neutra. Rejeita-se a ideia de que o progresso científico gera automaticamente benefícios sociais, superando e equação ciência e tecnologia como riqueza e bem-estar social. A relação exista, mas não é linear nem determinada por um caminho único (CEREZO, 2000). Tal aspecto havia sido deixado para segundo plano no conceito de Tecnologia Apropriada, que pode ser considerada um embrião do movimento de Tecnologia Social. Diversas concepções do conceito de Tecnologia apropriada foram desenvolvidas nas décadas de 1960 e 1970 como resposta às tecnologias dos países dominantes. Dagnino, Brandão e Novaes (2004) destacaram que a Tecnologia Apropriada focava prioritariamente no produto, e não no processo. Para eles a inovação não pode ser pensada em algo feito num lugar e aplicado em outro, mas como um processo desenvolvido no lugar onde essa tecnologia vai ser utilizada, pelos atores que irão utilizá-las" (DAGNINO, BRANDÃO e NOVAES, 2004, pp. 56-57). A Tecnologia Social demanda foco no processo de produção, com objetivo último de emancipação dos atores envolvidos, diferentemente do processo gerencial das Tecnologias Convencionais, que buscam otimizar e aumentar a eficiência do projeto, isoladamente.

A Tecnologia Social, por focar no processo, está entre as tecnologias menos visíveis. Sua menor visibilidade se dá pelo fato de estar ligada ao conceito de Economia Solidária e seus empreendimentos, que, em última instância, visam posicionar e viabilizar economicamente e de forma justa pessoas e setores produtivos que se encontram à margem dos principais mercados. Diferente das empresas convencionais do setor privado, cuja finalidade última é extrair mais-valia da força de trabalho para gerar lucro aos proprietários dos meios de produção, a Economia Solidária tem por objetivo gerar inclusão social, trabalho 
e renda (DAGNINO, 2004), o que confronta diretamente e lógica de acumulação de capital característica do sistema produtivo capitalista. Define-se Tecnologia Social como

Conjunto de técnicas e metodologias transformadoras, desenvolvidas e/ou aplicadas na interação com a população e apropriadas por ela, que apresentam soluções para inclusão social e melhoria das condições de vida (INSTITUTO DE TECNOLOGIA SOCIAL, 2004, p.130).

A Tecnologia Social, ao compartilhar com a Economia solidária a premissa da inclusão social, se diferencia das tecnologias convencionais por objetivar, em última instância, a justiça social, que por sua vez é também um dos principais objetivos do desenvolvimento de um território. Dagnino (2004, p.20) reforça que a tecnologia convencional é apropriada e desenvolvida pelas empresas privadas para fins de maximização do lucro. A Tecnologia Convencional possui como características, ser:

- mais poupadora de mão de obra;

- mais intensiva em insumos sintéticos do que seria conveniente;

- possui escalas ótimas de produção sempre crescentes

- sua cadência de produção é dada pelas máquinas

- ambientalmente insustentável

- possui controles coercitivos que diminuem a produtividade.

Já a Tecnologia Social é Dagnino (2004, p. 23):

- adaptada a pequeno tamanho;

- liberadora do potencial físico e financeiro; e da criatividade do produtor direto;

- não discriminatória (patrão $\times$ empregado);

- capaz de viabilizar economicamente os empreendimentos autogestionário e as pequenas empresas;

- orientada para o mercado interno de massa;

- deve ser adaptada ao reduzido tamanho físico e financeiro;

- não discriminatória; liberada da diferenciação - disfuncional, anacrônica e prejudicial nos ambientes autogestionários.

Ao estabelecer a ponte com as TIC que caracterizam o cenário comunicacional contemporâneo, verificar se uma estrutura comunicacional de um território é favorável ao desenvolvimento significa identificar se as tecnologias midiáticas se aproximam mais do conceito de tecnologia convencional ou da tecnologia social. Entende-se, portanto, que um cenário comunicacional mais favorável ao desenvolvimento de um território demanda que a comunicação seja tratada como uma Tecnologia Social, o que favorecerá que esta gere as possibilidades para que determinada sociedade para, em última instância, ser capaz de refletir de definir os rumos de sua realidade, em um ambiente de equidade acesso à de informação; equidade na voz dos distintos grupos sociais; e adaptação às questões locais. 


\section{MÉTODO}

A pesquisa caracteriza-se como exploratória, visto que propõe explorar teoricamente proposituras metodológicas para avaliação da estrutura de comunicação de um território a partir de parâmetros de uma comunicação para o desenvolvimento. O delineamento da pesquisa é bibliográfico. A premissa de análise fundamenta-se, inicialmente, na perspectiva de Dagnino (2004) sobre Tecnologia Social. Wolton (2005), que sugere que a comunicação é formada pelos campos técnico, econômico, social e cultural, que foram definidas como as unidades macro de análise no método proposto neste artigo.

\section{RESULTADOS: PROPOSTA METODOLÓGICA}

O propósito deste artigo é propor um método de análise para verificar se o ambiente comunicacional de determinado território é favorável ao desenvolvimento. Parte-se da premissa que a estrutura de um ambiente midiático favorável aos processos de desenvolvimento deva aproximar-se das premissas de Tecnologia Social, e não da mera Tecnologia convencional, reforçando que o cenário midiático contemporâneo é marcado pela tecnologia, mas especificamente pelas TIC.

Primeiramente, propõe- se no método de análise a delimitação geográfica. A proposta é sempre aplicar o método na escala país, inicialmente, para então aplicar à dimensão regional ou local, para que seja possível, sob o prisma comparativo, compreender a dinâmica e formas de apropriação do sistema de mídia localmente sem desconsiderar que grande parte das decisões referentes a legislação, estrutura de telecomunicações e regulamentações ocorrem na esfera federal. Observar apenas as características locais para um objeto que é de interesse estratégico nacional geraria uma limitação na leitura dos resultados. O enfoque local demanda a análise dos veículos de comunicação existentes no território delimitado, bem como a consideração de fluxos de comunicação alternativos às mídias convencionais, que potencialmente podem se configurar como Tecnologias Sociais.

A proposta consiste em analisar o sistema de mídia a partir das dimensões propostas por Wolton (2005) - técnica, econômica e sociocultural - e verificar se os parâmetros que caracterizam a Tecnologia Social se manifestam nas dimensões definidas, conforme Quadro 1. 


\begin{tabular}{|c|l|}
\hline Dimensões macro & \multicolumn{1}{c|}{ Parâmetros } \\
\hline \multirow{4}{*}{ Técnica } & Estrutura física de telecomunicações. \\
\cline { 2 - 3 } & Acesso a equipamentos, transmissão. \\
\cline { 2 - 3 } Econômica & Tipologia e origem dos equipamentos. \\
\hline \multirow{5}{*}{ Social e cultural } & $\begin{array}{l}\text { Existência de veículos locais, de propriedade e gestão } \\
\text { locais/ regionais, o que representa uma desconcentração } \\
\text { da propriedade de mídia. }\end{array}$ \\
\cline { 2 - 3 } & $\begin{array}{l}\text { Viabilidade de empresas de mídia locais, de pequeno } \\
\text { porte. }\end{array}$ \\
\cline { 2 - 2 } & Políticas de concessões. \\
\hline \multirow{5}{*}{$\begin{array}{l}\text { Gestão por governança, como nos modelos } \\
\text { comunitários, públicos e educativos. }\end{array}$} \\
\cline { 2 - 2 } & Existência de programação produzida localmente. \\
\cline { 2 - 3 } & Processo de produção do conteúdo. \\
\cline { 2 - 2 } & Conteúdo adequado à demanda da população local. \\
\cline { 2 - 3 } & $\begin{array}{l}\text { Existência de processos de comunicação locais } \\
\text { independentes das grandes mídias. }\end{array}$ \\
\hline
\end{tabular}

Quadro 1 - Parâmetros de análise.

Fonte: Elaborado pelos autores (2018).

Para atender aos parâmetros, a análise demanda coleta de dados primários e secundários: entrevistas de abordagem qualitativa com os atores envolvidos no processo e busca em bases documentais e análise de conteúdo da programação, respectivamente.

A propositura visa possibilitar uma análise global minimizando leituras parciais nas quais o enfoque em apenas um dos aspectos (técnico, econômico ou cultural), visando superar perspectivas simplistas como apenas o acesso às TIC, por exemplo.

Por meio das dimensões propostas, torna-se possível verificar se são atendidos os preceitos de Tecnologia Social elencados por Dagnino (2004). A dimensão técnica revela o nível de dependência dos recursos tecnológicos gerados pela Tecnologia Convencional que, na sociedade contemporânea, consiste no modelo dominante. Dagnino (2004) destaca que a Tecnologia Social se caracteriza pela capacidade de viabiliza economicamente os empreendimentos autogestionários e as pequenas empresas. Ao transpor tal diretriz para o ambiente midiático, especialmente para a análise da diretriz econômica, uma concentração dos veículos de comunicação em grandes empresas da mídia afasta o modelo do paradigma da Tecnologia Social. Já um cenário com diversidade de veículos, especialmente pequenas empresas de atuação regional, aproxima-se do conceito proposto por Dagnino (2004). A existência de veículos de natureza comunitária, por exemplo, é algo compatível com as ideias do autor. Portanto, quanto mais pluralidade, menos concentração e mais diversidade de veículos, mais próximo o cenário midiático torna-se afim da Tecnologia Social e, portanto, 
favorável para os processes de desenvolvimento local e regional. Portanto, quanto maior a concentração dos meios de comunicação, maior a aderência à Tecnologia Convencional. $\mathrm{O}$ ganho de escala, por exemplo, é algo que se observa nos grandes grupos de mídia, cujas equipes de produção geram conteúdo para vários veículos.

A dimensão social e cultural, por fim, observa a natureza dos conteúdos produzidos e veiculados no sistema de mídia. A presença de conteúdo local e/ou regional demonstra tanto uma orientação ao que Dagnino (2004) denomina de mercado interno, compreendido como os interesses da população local, quanto adere ao pensamento de Wolton (2005), que destaca que as diferenças locais se fazem mais visíveis à medida que as mensagens se mundializam.

Em suma, compreender a estrutura de mídia de um território é aspecto fundamental para verificar o papel que a comunicação exerce nos processos de desenvolvimento.

\section{CONSIDERAÇÕES FINAIS}

Após o percurso apresentado que estabelece relação entre comunicação, desenvolvimento e tecnologia social, retoma-se o objetivo central deste artigo que consiste em esboçar uma proposta metodológica para averiguar se o ambiente comunicacional de um território é favorável ao desenvolvimento.

A aproximação dos parâmetros de análise com as premissas da Tecnologia Social parece ser um caminho que permite superar a visão fractal sobre os processos. Outro aspecto relevante é que o método propõe uma comparação entre a localidade ou região estudada com a escala país, visto que um sistema de comunicação é algo estratégico e de interesse para a nação. Para compreender a dinâmica de uma localidade faz-se necessário compreender o contexto e as macrovariáveis que incidem sobre o local, de maneira a evitar leituras deslocadas de contexto sócio- histórico mais amplo.

A partir da proposta teórica sugerida, recomenda-se que pesquisas futuras apliquem as premissas metodológicas sugeridas para validação e aprimoramento a proposta, recomendação sustentada na ideia de que a ciência é dinâmica e construída a partir do debate teórico e aplicação dos modelos teórico-conceituais propostos.

A contribuição da comunicação para o desenvolvimento territorial pressupõe sua apropriação enquanto Tecnologia Social, cujo impacto depende do deslocamento da percepção sobre a inovação e a tecnologia do plano instrumental para suas funções sociais. Nesse sentido, o ambiente comunicacional propício ao desenvolvimento de um território associa-se aos parâmetros definidores da Tecnologia Social e à efetividade de políticas 
públicas aptas a engendrar as condições necessárias à sua implementação. O diagnóstico do ambiente comunicacional presente em um território é o procedimento necessário para a produção dos subsídios para políticas públicas concernentes à multidimensionalidade do processo de desenvolvimento.

\section{REFERÊNCIAS}

BRETON, Philippe. L'utopie de la communication. Le mythe du village planétaire. Paris: La Decouverte Poche, 1997.

BRINDE, Amparo Cavidad. Que comunicación para cuál desarrollo? Congresso Mundial de Comunicación para el Desarrollo. Colombia, 2006.

BOUDIN, Alain. A questão local. Rio de Janeiro: DP\&A, 2001.

CEREZO, J. Lopes Ciencia, tecnología y sociedad: el estado de la cuestión en Europa y Estados Unidos. Revista Iberoamericana de Educación, n. 18, p. 41-68, 2000.

DALLABRIDA, Valdir Roque. Economia, Cultura e Desenvolvimento: uma primeira aproximação sobre as origens teóricas da abordagem do tema. Revista Brasileira de Gestão e Desenvolvimento Regional, v. 7, n. 2, p. 282-299, mai-ago/2011, Taubaté, SP, Brasil. Recuperado em 10 de dezembro, 2017, de http://www.rbgdr.net/revista/index.php/rbgdr/article/view/432/249

DAGNINO, Renato. A Tecnologia Social e seus desafios, In: FBB; Tecnologia Social: uma estratégia para o desenvolvimento, Rio de Janeiro: FBB, 2004. Disponível em: < http://books.scielo.org/id/7hbdt/pdf/dagnino-9788578793272-04.pdf> Acesso em: 07 nov. 2017.

DAGNINO, R.P.; BRANDÃO, F.C.; NOVAES, H.T. (2004) Sobre o Marco Analítico-conceitual da Tecnologia Social. In: FBB. Tecnologia Social: uma estratégia para o desenvolvimento. Rio de Janeiro: FBB, 2004. Disponível em: < <http://www.mom.arq.ufmg.br/mom/18_ref_capes/arquivos/arquivo_110.pdf > Acesso em: 07 nov. 2017.

DEBORD, G. Sociedade do espetáculo. Rio de Janeiro: Contraponto, 2000.

FURTADO, Celso. A dialética do desenvolvimento. Rio de Janeiro: Fundo de Cultura, 1964.

G1. Facebook atinge os 2 bilhões de usuários. G1, 27 jun. 2017, Disponível em: < https://g1.globo.com/tecnologia/noticia/facebook-atinge-os-2-bilhoes-de-usuarios.ghtml> Acesso em: 03 de jan. 2018.

GUARESCHI, Pedrinho A. O direito humano à comunicação: pela democratização da mídia. Petrópolis, RJ: Vozes, 2013.

INSTITUTO DE TECNOLOGIA SOCIAL. Reflexões sobre a construção do conceito de tecnologia social. In: DE PAULO, A. et al. Tecnologia social: uma estratégia para o desenvolvimento. Rio de Janeiro: Fundação Banco do Brasil, 2004.

LIMA, Venâncio A. de. Mídia, crise política e poder no Brasil. São Paulo: Fundação Perseu Abramo, 2006. 
LIPOVETSKY, Gilles. Metamorfoses da cultura liberal: ética, mídia e empresa. Porto alegre: Sulina, 2004.

MENEZES, José Eugenio de O. Processos de mediação: da mídia primária à mídia terciária. Comunicara. V.4, n.1, 2004. Disponível em: <https://casperlibero.edu.br/wpcontent/uploads/2014/07/Processos-de-media\%C3\%A7\%C3\%A3o.pdf> Acesso em: 03 jan.2018.

PANOS LONDON. The case for communication in sustainable development. London, Panos London, 2007.

RODRIGUES, Ivete; BARBIERI, José Carlos. A emergência da tecnologia social: revisitando o movimento da tecnologia apropriada como estratégia de desenvolvimento sustentável. Revista de Administração Pública, 42(6), 1069-1094, 2008.

VARGAS, Milton. Técnica, tecnologia e ciência. Revista Educação e Tecnologia. Pp.178-183, 2003. Disponível em: 〈http://revistas.utfpr.edu.br/pb/index.php/revedutec-ct/article/viewFile/1084/687> Acesso em: 15 de nov.2017.,

WOLTON, Dominique. Il faut sauver la communication. Paris, Flammarion, 2005.

Original recebido em: 03 de fevereiro de 2019

Aceito para publicação em: 29 de dezembro de 2019

\section{Monica Franchi Carniello}

Doutora em Comunicação e Semiótica (PUCSP). Possui pós-doutorado pela Universidade Metodista (UMESP) e pela Universidade do Minho - Portugal. Professora do Mestrado em Planejamento e Desenvolvimento Regional e do Mestrado em Gestão e Desenvolvimento Regional da Universidade de Taubaté. Professora da Fatec Pindamonhangaba.

Moacir José dos Santos

Doutor em História (UNESP). Possui pós-doutorado pela Universidade do Minho - Portugal. Professor do Mestrado em Planejamento e Desenvolvimento Regional e do Mestrado em Gestão e Desenvolvimento Regional da Universidade de Taubaté. Professor do Centro Universitário Módulo.

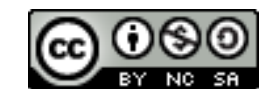

Esta obra está licenciada com uma Licença

Creative Commons Atribuição-NãoComercial-CompartilhaIgual 4.0 Internacional 